\title{
Bertrand Oligopoly And Factors Markets With Scarcity And Price Controls
}

\author{
Randall E. Waldron, Ph.D., University of South Dakota, USA
}

Michael A. Allgrunn, Ph.D., University of South Dakota, USA

\begin{abstract}
In an earlier article, we reported the results of a classroom experiment simulating price competition in an oligopoly with differentiated goods. That study raised some questions that we were unable to address at that time. For this current study, we have adapted the experiment to further explore the effects of scarcity in the input markets, and to study the effects of price controls in these markets. We find that scarcity in an input market has the expected directional effect on prices in both input and output markets, but not necessarily the magnitude expected; we further find that price controls have only some of the effects expected. In the current experiment, we increased the number of rounds of the game to allow more opportunity for convergence to a stable outcome, and to allow for three distinct phases of the game: initial rounds in which inputs were abundantly available, subsequent rounds in which one input's supply was dramatically reduced, and final rounds in which a price floor was established on the one input which remained abundant. As expected, firms played Nash/Bertrand strategies in the early rounds. However, the shock caused by reducing the availability of capital took many rounds for full adjustment, with both output prices and the equilibrium rental rate of capital rising consistently and gradually toward their projected equilibria over ten rounds, although even then capital prices did not rise enough to absorb all firm profits. Surprisingly, establishing a minimum wage did not have the anticipated effect of balancing payments between labor and capital; instead, the minimum wage completely disrupted the trend of an increasing rental price of capital and reduced it to zero, while creating volatility in profits without consistently eliminating them. Overall, we find that most of our anticipated results ultimately obtain, but adjustments to variations in market conditions are neither immediate nor perfectly consistent with the predictions of theory.
\end{abstract}

Keywords: Economic Experiments; Bertrand Competition; Economic Pedagogy; Factor Markets.

\section{INTRODUCTION}

$\mathrm{n}$ an earlier article, we reported the results of a classroom experiment simulating price competition in an oligopoly with differentiated goods (Waldron, Allgrunn, and Pei, 2010). The original contribution of that paper was the incorporation of input markets into the more common analysis of oligopolistic markets for a final good. We were interested in both the pedagogical value of the experiment as well as the results of the experiment itself; we found that the experiment enhanced learning, and that for the most part, the results conformed to the expectations generated by our model. However, that study also raised some questions that we were unable to address at that time. For this current study, we have adapted the experiment to further explore the effects of scarcity in the input markets, and to study the effects of price controls in these markets. We find that scarcity in an input market has the expected directional effect on prices in both input and output markets, but not the magnitude expected; we further find that price controls have only some of the effects expected.

Since Vernon Smith's (1962) seminal work, many authors have used experimentation to test theories about market behavior. Some of these have focused on oligopoly simulations and price competition. Dufwenberg and Gneezy (2000) look at price competition, as do Kruse et al. (1994). With classroom experiments like ours, many authors also assess pedagogical effectiveness (see, for example, Gremmen and Potters, 1997; Holt, 1999; Ortmann, 2003; and Kruse et al., 2005). In this current paper, we do not attempt to measure the benefit of the experiment for 
teaching purposes, but we do note that this work emerges from our pedagogical efforts in managerial and labor economics. No other studies that we are aware of integrate factor markets in a way that is similar to what we do.

\section{BACKGROUND}

For the original experiment, we created a game simulating an environment in which three firms acted as Bertrand competitors in the market for their output, for which we assumed interdependent demand functions reflecting significant but imperfect substitutability between the goods. We further assumed that the firms used identical Leontief production techniques with capital and labor, which had to be procured in input markets. Firms bid for inputs, which were supplied to the market perfectly inelastically. The experiment featured repeated rounds of the game, and in each round firms submitted a demand schedule for their inputs and set a price for their output. We wrote a computer program to resolve the game, determining the market demands for each firm's output and the equilibrium price for each input, along with each firm's production capacity, depending on the factors each had obtained based on their bids. Firms were assumed to sell the lesser of the demand for their output and their production capacity, and the computer program then reported profits for each round.

Our primary interest in the initial experiment, besides evaluating its pedagogical value for student learning, was to observe how well the usual Bertrand models and Nash equilibrium predict firm behavior, particularly when we introduce scarcity in the input markets. While classroom experiments with oligopolistic price competition are probably widely used, we are unaware of any that also incorporate input markets at the same time. We began the earlier experiment by having both inputs supplied at abundant quantities that should easily have enabled firms to obtain all the factors desired at zero or nearly zero cost, and we expected to observe firms play the Nash/Bertrand strategies that obtain under costless production conditions. In fact, this is almost precisely what the experiment participants did.

We then moved to a number of rounds in the game in which one of the factors (labor) became significantly scarcer. We expected to see the market prices for output rise dramatically, and we expected the firms to bid up the price of the scarce input to the point that wage payments for the labor absorbed all the potential profits. We derived the equilibrium of the game based on a symmetrical distribution of the inputs among the three firms and rationalized the zero-profit output by noting that each firm had an incentive to bid higher for the scarce input until the wage rate reached the output price. The game is complicated significantly by the simultaneous choices of output price and input bids, but we anticipated that firms would bid away profits in search of scarce inputs in much the same way that firms in Bertrand competition bid away profits by lowering their output price. The result is interesting and novel, because Bertrand competitors with differentiated products that are able to produce at constant cost (as, say, price takers in input markets) are generally found to earn positive economic profits. The initial experiment was designed to test whether in fact this anticipated result obtained in practice.

The results of the earlier experiment were mixed: firms in the rounds with abundant inputs did in fact move quickly towards the Nash/Bertrand predicted price levels, and when input scarcity was introduced, output prices rose and the equilibrium price of the scarce input increased as well. However, while the scarce input's price rose consistently, it never reached the levels we predicted. Here we effectively replicate the conditions of the first experiment, but extend the number of rounds played to allow more time for convergence to a stable outcome. We then extend the experiment further to test the effects of price controls in an input market.

\section{MODEL AND EXPERIMENT DESIGN}

For consistency in our analysis, we continue to use the same experimental framework developed in our previous study. We assume these linear demand functions:

$Q_{a}^{D}=100-3 p_{a}+p_{b}+p_{c}$

$Q_{b}^{D}=100-3 p_{b}+p_{a}+p_{c}$

$Q_{c}^{D}=100-3 p_{c}+p_{a}+p_{b}$ 
for the firms $\mathrm{a}, \mathrm{b}$, and $\mathrm{c}$. Each firm faces a production function showing output produced by capital and labor in fixed proportions:

$Q_{i}=\min \left\{K_{i}, L_{i}\right\}$

for $\mathrm{i}=\mathrm{a}, \mathrm{b}$, and $\mathrm{c}$. Factors of production are supplied perfectly inelastically in their respective markets, and firms bid for these resources competitively by submitting demand schedules which are then aggregated to form market demand. Factor supply then determines the equilibrium results.

When inputs are available at no cost and with no constraints, the Nash/Bertrand equilibrium has each firm producing 75 units, pricing output at 25 , and utilizing 75 units each of capital and labor, with each factor priced at zero. Firm profits are 1,875 each. If there is less than 225 units of labor or capital available, a symmetrical outcome that has each of the firms obtaining $1 / 3$ of the scarcest input is assumed, and we rationalize an equilibrium in which firms produce as much as they can, given the scarcity of the input, and that output prices rise accordingly. We also anticipate that firms will bid up the price of the scarce input to equal the price of the output. (The argument for this equilibrium outcome is developed more fully in Waldron, Allgrunn, and Pei, 2010).

We conducted this experiment in a single extended class period in a graduate level class, with students being assigned to the three "firms" randomly. Twenty one rounds of the game were conducted following a brief explanation of the game, and students were told that a modest portion of their grade might depend on game performance to induce a serious effort. Students were not explicitly provided with specific parameters of the game, such as demand functions and factor endowments, but each round's information was displayed on a screen observable by everyone, so inferring factor availability in particular was fairly easy. The first six rounds of the game were played with "abundant" factor endowments of $\mathrm{L}=\mathrm{K}=240$; in rounds $7-16$ total capital availability was constrained to $K=120$, with labor remaining at $\mathrm{L}=240$. Given participants' inexperience, we assumed it would take a few rounds of experimentation for players to gravitate towards the equilibrium; from our own experience with the prior experiment, we believed it might take even more rounds to approach the equilibrium with the capital supply constraint.

Finally, anticipating that the scarce input would eventually capture all of the possible rents, absorbing all potential firm profit, we conducted rounds $17-21$ with price controls in the labor market, establishing a minimum wage of 30 for each unit of L hired. Absent this price control, we expected the rent for capital, in short supply, to be bid up to 60; thus we anticipated that the price control would redistribute factor payments more evenly, without causing a change to output levels or prices. These conditions are summarized in Table 1 below, with Q showing firm output, $p$ being the price of the final good, w representing labor's wage rate, and $r$ showing the rental price of capital:

Table 1: Summary of Experimental Conditions and Expected Outcomes

\begin{tabular}{|c|c|c|}
\hline Rounds & Conditions & Anticipated Outcomes \\
\hline $1-6$ & $\begin{array}{l}\mathrm{L}=\mathrm{K}=240 \\
\text { No price controls }\end{array}$ & $\begin{array}{l}w=r=0 \\
L=K=Q=25 \text { for each firm } \\
p=25 \text { for each firm } \\
\text { Profits }=1875 \text { for each firm }\end{array}$ \\
\hline $7-16$ & $\begin{array}{l}\mathrm{K}=120 \\
\mathrm{~L}=240 \\
\text { No price controls }\end{array}$ & $\begin{array}{l}r=60 \\
w=0 \\
L=K=Q=40 \text { for each firm } \\
p=60 \text { for each firm } \\
\text { Profits }=0 \text { for each firm }\end{array}$ \\
\hline $17-21$ & $\begin{array}{l}\mathrm{K}=120 \\
\mathrm{~L}=240 \\
\text { Minimum wage for } \mathrm{L}: 30\end{array}$ & $\begin{array}{l}r=30 \\
w=30 \\
L=K=Q=40 \text { for each firm } \\
p=60 \text { for each firm } \\
\text { Profits = } 0 \text { for each firm }\end{array}$ \\
\hline
\end{tabular}




\section{EXPERIMENT RESULTS}

We show the results of our experiment in the figures below. Figure 1 shows the prices for the final good set by each firm for each round, along with our anticipated Nash/Bertrand equilibrium price. Figure 2 shows profits for each firm, along with our anticipated equilibrium profits. Figure 3 displays the equilibrium labor wage and rental price of capital in the input markets, as determined by the aggregated firm demand schedules and the fixed quantities of inputs available for supply; we also display the anticipated equilibrium prices in the input markets.

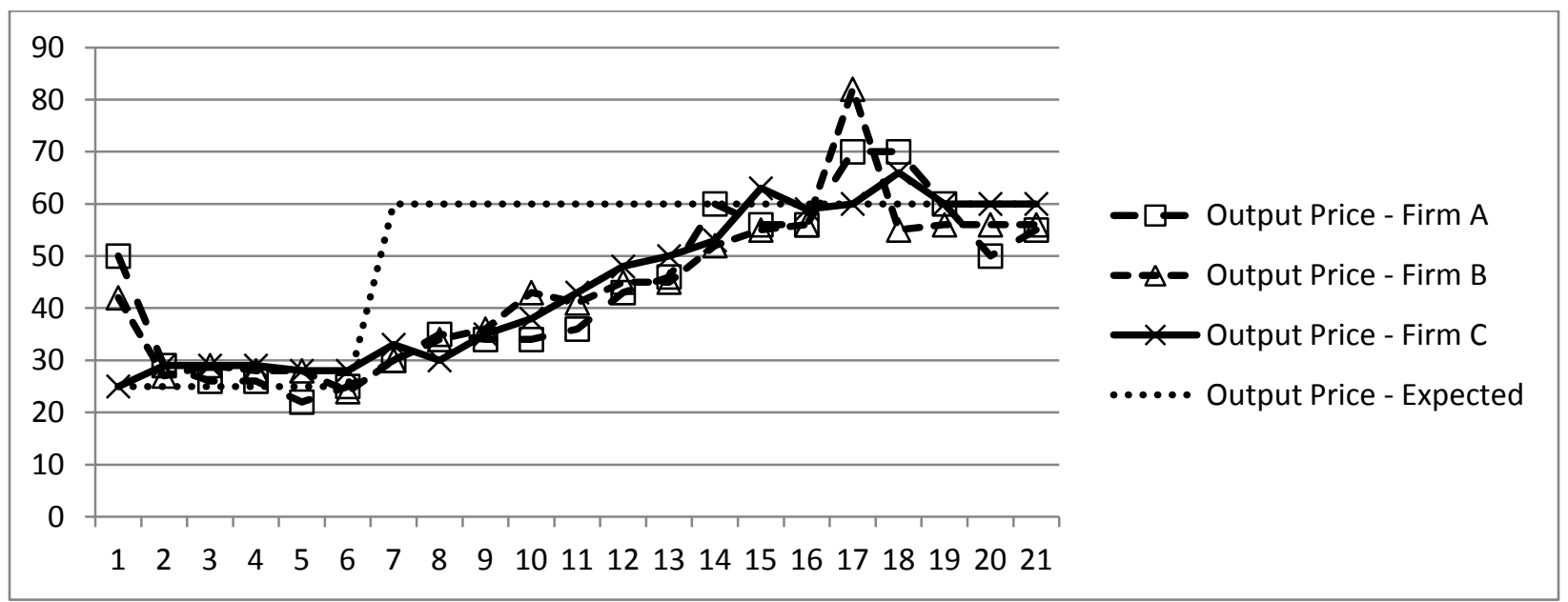

Figure 1: Output Prices

After a wide variance in prices in the first round, all firms began pricing at or very near the expected price of 25 , and continued to do so over the initial six rounds. Our previous experiment had showed an apparent reluctance on the part of firms to adjust prices to reflect the supply conditions when an input's availability was severely limited, and once again we find that output prices did not adjust rapidly following the supply shock limiting capital's availability. Nonetheless, beginning in round seven prices did begin to rise remarkably consistently for ten rounds until they reach the expected equilibrium. Once the wage controls were introduced in round seventeen, there was initially a continued push for higher prices by a couple of the firms, but it is unclear whether the players were motivated by an interest in recapturing the profit that would now go to pay wages, or simply continuing the trend from previous rounds. In any case, firms quickly reverted back to near-equilibrium pricing during the final rounds of the game, whereupon it appears that convergence in pricing strategies had been reached.

One might expect that the initial rounds, and the final rounds, would have shown profit levels that were as consistent as the pricing strategies, but this turns out not to be the case, as shown in Figure 2. Firms were simultaneously choosing output prices and demand schedules for inputs, and these appear to have been somewhat difficult for firms to coordinate, leading to volatility in profits. Relatively small differences in factor bidding had the potential to leave firms with either costly excess capacity or insufficient capacity to meet the demand generated by output prices. Firm profits remained positive but generally below the expected levels in rounds $2-6$, and typically lower still but usually positive during the remaining rounds of the game. There is an overall downward trend in profits within the variability in rounds $7-16$, but it is unclear whether profits were in fact approaching zero as predicted. In the final rounds of the game, when the minimum wage was introduced, profits became more volatile than in the rounds immediately preceding the wage control, but did not regularly go to zero. 


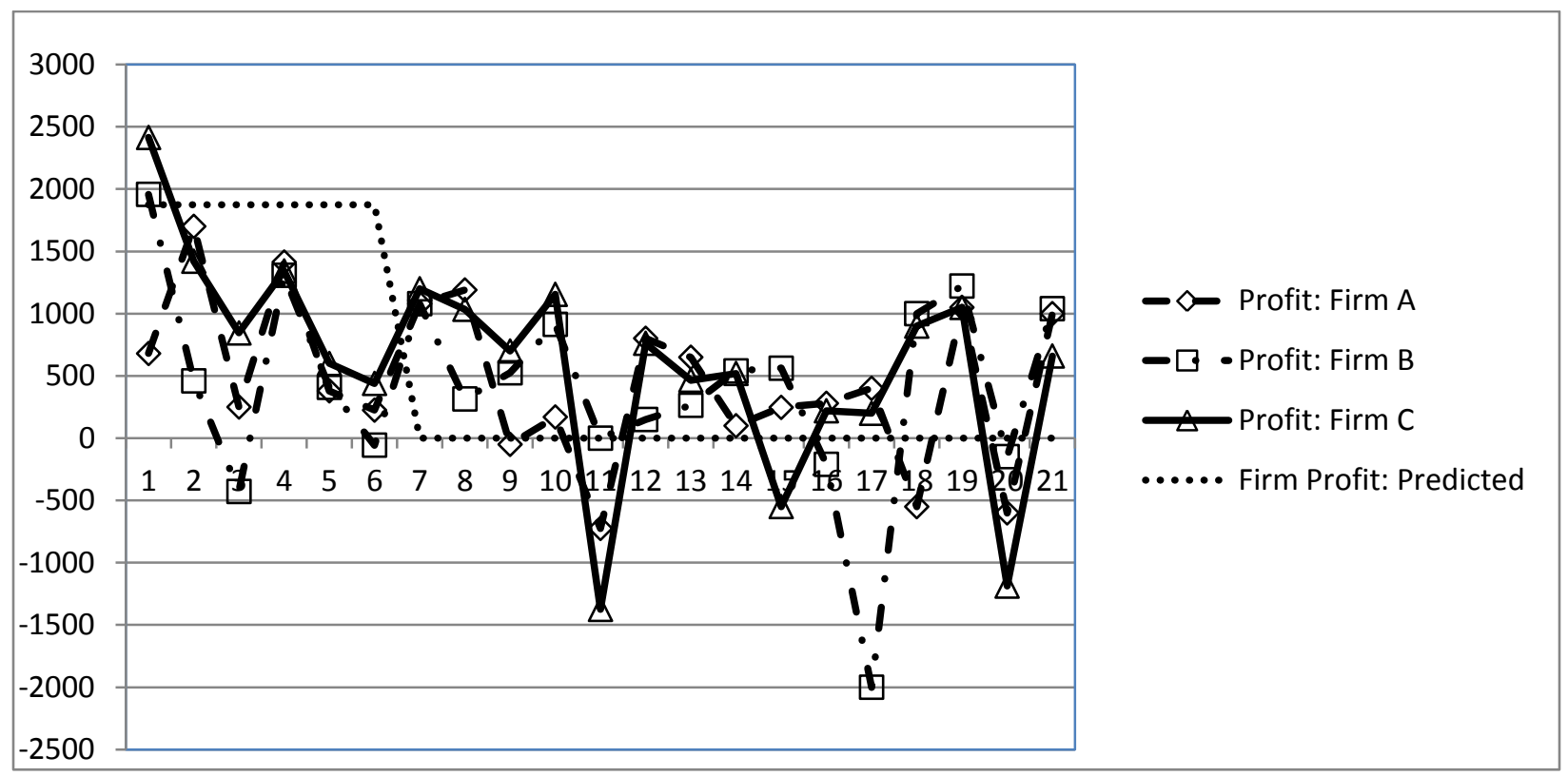

Figure 2: Firm Profits

Initial bidding for inputs kept wage and rental rates near zero, but not precisely zero, with firms possibly thinking that a small bid above zero might deprive competitors of their factors of production. Notwithstanding the coordination problems noted above, however, it appears that firms did not attempt to monopolize input markets by bidding very high prices in the first few rounds. The introduction of the capital supply reduction ultimately pushed up the equilibrium price of capital, although even after ten rounds it had not risen to the point of capturing all firm profits by equaling the output price. The wage rate quickly moved to zero and generally stayed there as the rental price of capital smoothly and consistently rose between rounds $7-16$. Interestingly, the minimum wage requirement did not have the anticipated effect of splitting the distribution of factor payments between labor and capital; instead, firms immediately stopped bidding up the rental rate of capital, and the equilibrium rate moved to zero and stayed there for the remainder of the game.

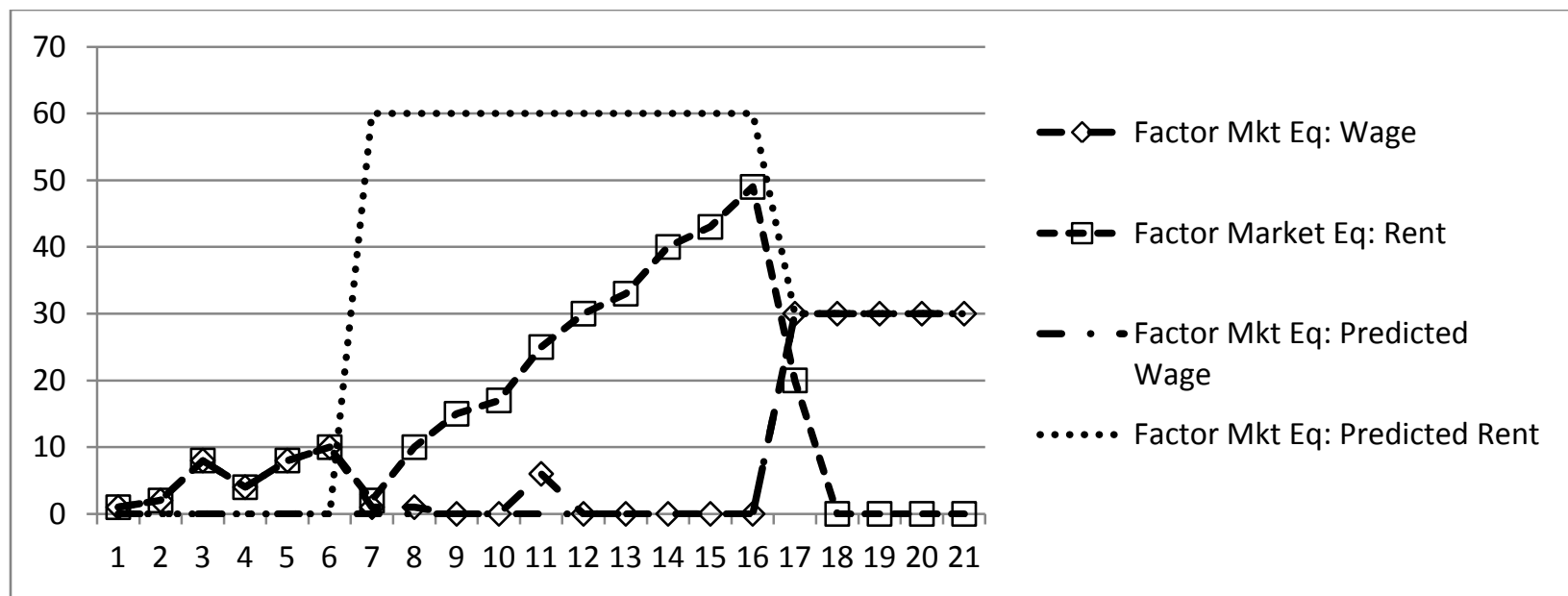

Figure 3: Labor Wages and Capital Rents 


\section{CONCLUSION}

Our earlier experiment confirmed that firms in a simulation would play the Nash/Bertrand strategies that theory suggests when inputs are freely available, but left questions about how constrained input availability would alter the outcomes, and how price controls on inputs might further alter behavior. In the current experiment, we increased the number of rounds of the game to allow more opportunity for convergence to a stable outcome, and to allow for three distinct phases of the game: initial rounds in which inputs were abundantly available, subsequent rounds in which one input's supply was dramatically reduced, and final rounds in which a price floor was established on the one input which remained abundant. As expected, firms played Nash/Bertrand strategies in the early rounds. However, the shock caused by reducing the availability of capital took many rounds for full adjustment, with both output prices and the equilibrium rental rate of capital rising consistently and gradually toward their projected equilibria over ten rounds, although even then capital prices did not rise enough to absorb all firm profits. Surprisingly, establishing a minimum wage did not have the anticipated effect of balancing payments between labor and capital; instead, the minimum wage completely disrupted the trend of an increasing rental price of capital and reduced it to zero, while creating volatility in profits without consistently eliminating them. Overall, we find that most of our anticipated results ultimately obtain, but adjustments to variations in market conditions are neither immediate nor perfectly consistent with the predictions of theory.

\section{AUTHOR INFORMATION}

Randall Waldron received his Ph.D. from Vanderbilt University in 1994 and holds a B.A. with majors in economics and political science from Northwestern University. He has been employed at The University of South Dakota since 1994. His teaching and research interests focus on applied microeconomics, including game theory, experimental and managerial economics. During the 2006 - 2007 academic year, he was a Fulbright Lecturer at Beijing Jiaotong University in China while on sabbatical from USD. E-mail: Randall.Waldron@usd.edu. Corresponding author.

Michael Allgrunn has been an assistant professor of economics at The University of South Dakota since 2006. His specialties are Econometrics and Labor economics, with research interests in economic pedagogy, immigration, and unemployment insurance. He received his Ph.D. from Michigan State University. E-mail: Mike.Allgrunn@usd.edu

\section{REFERENCES}

1. Dufwenberg, M., \& Gneezy, U. (2000). Price Competition and Market Concentration: An Experimental Study. International Journal of Industrial Organization, 18, 7-22.

2. Gremmen, H., \& Potters, J. (1997). Assessing the Efficacy of Gaming in Economics Education. Journal of Economic Education, 28, 291-303.

3. Holt, C. (1999). Teaching Economics with Classroom Experiments: A Symposium. Southern Economic Journal, 65:3, 603-610.

4. Kruse, J., Oxdemir, O., \& Thompson, M. (2005). Market Forces and Price Ceilings: A Classroom Experiment. International Review of Economics Education, 4:2, 73-86.

5. Kruse, J., Rassenti, S., Reynolds, S., \& Smith, V. (1994). Bertrand-Edgeworth Competition in Experimental Markets. Econometrica, 62:2, 343-371.

6. Ortmann, A. (2003). Bertrand Price Undercutting: A Brief Classroom Demonstration. Journal of Economic Education, 34, 21-26.

7. Smith, V. (1962). An Experimental Study of Competitive Behavior. Journal of Political Economy, 70:2, 111-137.

8. Waldron, R., Allgrunn, M., \& Pei, G. (2010) Experiments in Bertrand Competition with Factor Markets. Journal of Business \& Economics Research, 8:3, 123-130. 